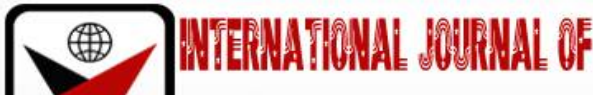

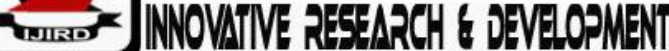

ISSN 2278 - 0211 (Online)

\section{Improving Tertiary Institutions' Internally Generated Revenue through Business Partnerships with Private Sector Establishments: A Case Study of Selected Tertiary Institutions in Nigeria}

\author{
Okonkwo Dyke A. R. \\ Federal Polytechnic, Nekede, Owerri, Nigeria \\ Ejiogu Stella I. \\ Department of Physical Science Education, Imo State University, Owerri, Nigeria \\ Osakpa D. U. \\ Department of Social Science Education, Imo State University, Owerri, Nigeria
}

\begin{abstract}
:
This paper investigated improving tertiary institutions' internally generated revenue through business partnerships with private sector establishments in Nigeria. The objective of this paper was to ascertain if managers of tertiary institutions in Nigeria were aware of and created business opportunities for improving the internally generated revenue of their institutions. The population of the study consisted of 4,950 managers and senior staff of selected tertiary institutions out of which a cluster sample of 400 was identified for data collection. A Likert's 4-point rating scale (Tertiary Institutions Internally Generated Revenue Scale, TIIGRS) was constructed, validated and administered on the identified sample. A survey design was adopted for the study. There was a review of materials on institutional entrepreneurship, business partnerships, identification of business opportunities, internally generated revenue and tertiary institutions' capacity for setting up industries to manufacture products based on their research results and technological innovations. Four research questions and four null hypotheses were formulated to guide the study. Hypotheses were tested with the Chi-Square $\left(\mathrm{x}^{2}\right)$ Test of Independence and Cramer's v-statistic.
\end{abstract}

Keywords: Tertiary institutions' internally generated revenue private establishments

\section{Introduction}

This paper investigated factors that improve the internally generated revenue strategies of selected tertiary institutions in Nigeria by adopting strategies of companies that excel in the United States as analyzed in Built to Last (2002); especially going into partnerships with private sector establishments. The paper examined the possibility of adopting strategies of profit-making organizations in managing tertiary institutions that are non-profit-making. Tertiary institutions have their managerial or administrative culture-the committee system; sometimes blended with strategic management principles (Capson, 2008), cost-benefit analysis (Madumere, 1989 and Hindle, 2008) and total quality management principles (Bateman and Zeithaml, 1993 and Hindle, 2008). The problem is that in managing tertiary institutions, employees at all levels do not see themselves as co-owners of the institutions (Awe, 2008), unlike staff of companies that excel in the United States of America (Collins and Porras, 2002). There is, therefore, a fundamental difference between how these companies and tertiary institutions are managed although the two types of organizations share common characteristics (Oku, 2008 and Obi, 2004). These researchers identified common characteristics organizations share as: more than one person, cooperation between individuals as very necessary, a set of objectives to be accomplished, guidelines for implementation of policies, efficient allocation of limited or scarce resources, systematic arrangement of functions, an environment within which various activities are carried out, a common objective of achieving the set goals of an organization and survival, growth and sustainable profitability of the organization.

Funding tertiary institutions in Nigeria is a complex problem that can only be tackled by different sectors working together through cooperative effort such as business-NGOs, public-private joint ventures, cross-sector partnerships, global multi-stakeholder initiatives, governments, business, civil society, and development agencies should collaborate to leverage resources, stimulate innovation and maximize impact. However, effective collaboration between tertiary institutions and private-sector establishments with different approaches, missions, interests and cultures is difficult but not impossible (Udu, 2014). With these critical elements in place, 
business partnerships between tertiary institutions and private sector establishments can achieve the desired impact. Without them, these approaches are likely to under-perform or fail altogether.

The following research questions were formulated to guide the study: What are the characteristics of companies that excel in the United States that may enhance the internally generated revenue capacity of tertiary institutions in Nigeria? To what extent can the characteristics of companies that excel in the US be adopted to manage tertiary institutions in Nigeria? To what extent can tertiary institutions in Nigeria successfully go into profitable business partnerships with private-sector establishments? In which ways can these characteristics improve the internally generated revenue of Nigerian tertiary institutions? The following null hypotheses were formulated and tested at $p=<0.05$ : (1) Characteristics of companies that excel in the United States have no significant relationship with improving the internally generated revenue capacity of tertiary institutions in Nigeria (2) Characteristics of companies that excel in the US cannot significantly be adopted to improve the internally generated revenue of Nigerian tertiary institutions. (3) Nigerian tertiary institutions cannot significantly go into profitable business partnerships with private-sector establishments. (4) Characteristics of companies that excel in the US cannot significantly improve the internally generated revenue of tertiary institutions in Nigeria.

The researchers carried out relevant literature review and adapted the following concepts as analyzed in Built to Last (2002): they are premier institutions, crown jewels in the knowledge industry, widely admired by their peers, long track record of significant impact on the world around them, multiple product life cycles, multiple generations of leaders, resilience: ability to bounce back from adversities and defined autonomy in policies formulation and implementation.

Tertiary institutions in Nigeria, therefore, need to be aware of the aims of partnerships with private sector establishments. These include an understanding of the rationale for, and risks of, partnering and when, and when not, to partner; appreciation of policy drivers, societal roles and mindset of each sector; clarity over what constitutes a 'transactional collaboration', what is a 'genuine partnership' and where each may be appropriate, appreciation of the 'guiding principles', challenges and success factors behind effective partnership, understanding over what it takes to be a 'good' partner, and development of some of the skills and mindset required, understanding how to create agreements, implement, manage \& review partnerships successfully and familiarity with the 'Partnering Cycle', a framework for the development and management of partnerships (Udu, 2014). Useem (2015) argues that "if the conversation at this month's Business Civic Leadership Center's conference on emerging markets is anything to go by, then partnerships are not only helping to drive today's development agenda, but also hold the key to scaling the most successful of those projects in the future". The researcher identified the following five effective ways of forming partnerships: be frank about your goals, find flexible people, speak the language (business cultural practices), maintain a "spider web" of communication and remember the end goal.

This is why Zander (1990) argues that the willingness of members of a group to participate in their group's activities is determined by the strength of their motivation: the weight of the motive or desire, incentive or objective and perceived possibility that the incentive or objective can be achieved. This situation aptly applies to tertiary institutions. These arguments are supported by McClelland's (1993). Guest (2004), Francis (2008), Udu (2014) and Bawakyilenuo (2013) argue that investments and capital formation are the core drives of business growth. The researchers reviewed the following studies on tertiary institutions' rewards: McCormick and Tiffin (1974), Cole (2005) and Byars and Rue (1997). It is on the basis of this review that they conclude and support the treatment of employees as co-owners of tertiary institutions with opportunities to share in profit quotas and bonuses.

This will engender the spirit of effective commitment to the ideals of tertiary institutions, their efficiency, productivity, survival and growth. In addition, Ngwenya (2015) concluded that marrying PPP initiatives with a clearly defined active role to be played by tertiary institutions will be the right ingredient to ensuring the success of a country's economic development. He argues further that his worry is the passive participation of tertiary institutions in the economic development of the country. To him, the reason for the passive participation of tertiary institutions is structural. He observes and emphasizes that world-class universities are in the forefront of pioneering research and such partnerships because they are designed to last in perpetuity, invest more, look further ahead and hone the competitiveness of companies, universities and even regions. In short, they transform the role of research in the university for the $21^{\text {st }}$ century, anchoring it as a vital center of competence to help tackle social challenges and drive economic growth. He further concludes that the collaboration between industry and universities is left to the discretion of individual universities and industry. His arguments are supported by Okunamiri (2015).

The nature and structure of organizations (companies or universities) vary. However, whatever an organization is, they possess common features (Igwe, 1990; Obianuju and Obi, 2004; and Collins and Porras, 2002). Some organizations do very well and last-long; some not so well and so, fail and fizzle out, thereby cutting short their own lives, the expectations of their members and the general public. This should not be the fate of Nigerian tertiary institutions and this is why this paper argues that strategies of companies that excel in the USA should be adopted or adapted in managing tertiary institutions. Built to Last (2002) is a careful and thorough survey of the characteristics (habits) of visionary and very successful companies in the United States of America whenjudgedagainst the performance of other companies. Collins and Porras (2002) have identified eight characteristics or factors that make these companies excel (Fig. 1). 


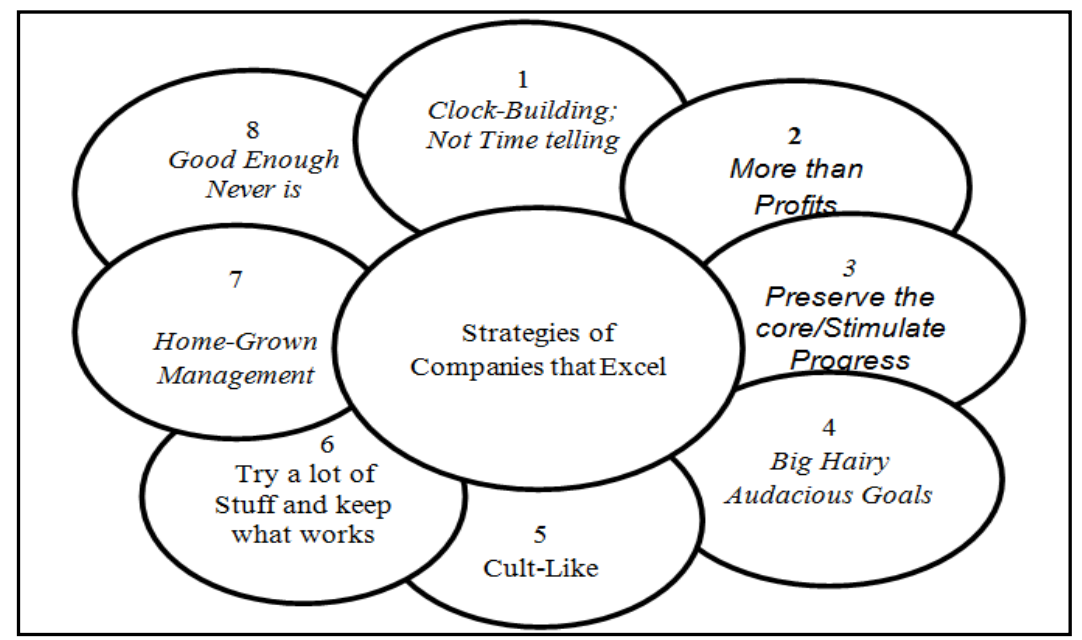

Figure 1: Characteristics of Highly Successfully Companies in the United States of America figure.

The significance of each of the above characteristics is highlighted in the following explanatory notes on the above

- Clock building, not time telling - The companies are not conscious of hours of work; rather what needs be done; a sort of clear-table policy.

- $\quad$ More than Profits - These companies are not only concerned about profits but an overall satisfactory service and products that guaranteed profits. Universities should not be satisfied with research results and technological innovations but physical products for the market and solution of problems.

- Preserve the Core/ Stimulate Progress - All efforts are made to preserve the core values of the companies while they keep striving for progress.

- $\quad$ Big hairy, audacious goals - Lofty goals are set for the companies that challenged both managers and staff to attain.

- Cult-like Culture - Everything is done to maintain the cultures of these companies; e.g. Speech patterns, dress codes, etiquette, etc of Oxford, Cambridge, Ibadan, ABU, Nsukka and so on.

- Try a lot of stuff and keep what works - This is based on pragmatism, having several options on the table as possible solutions to a problem.

- Home-grown Management - Assignments and responsibilities should be given to test and prove staffs who demonstrate commitment to the core values of the establishment or organization.

- Good enough never is - There is no level of excellence that the organization attains at which no more effort is made to improve.

Based on the application of the above characteristics to managing tertiary institutions in Nigeria, there is no reason why they should not commercialize their research findings and go to market with their products. By this, tertiary institutions can break the jinx of "he, who pays the piper, dictates the tune". So, the question is: what is the effect of these characteristics on tertiary institutions in Nigeria if they operate as profit-making establishments?

This question involves ethical considerations because tertiary institutions are not, primarily profit-making organizations. Another question is: What would it look like in the education system if tertiary institutions operate as profitmaking organizations? The most probable answer is that tertiary institutions will look like typical profit-making organizations which seemingly appear to negate their primary objectives. It is quite clear, too, that the characteristics discussed in Built to Last (2002) are quite illuminating by virtue of tertiary institutions' core values and the inability of proprietors to adequately fund them. After all, tertiary institutions are organizations with human beings and different idiosyncrasies just as profitmaking organizations. For one thing, if business organizations that cater for the material well-being of their customers and staff imbibe these habits in order to do well and last long, what about tertiary institutions that cater for their members' material well-being; intellectual development, accumulation of and dissemination of knowledge for human progress?

\section{Methodology}

A survey design was adopted for this study. The population of the study consisted of 4,950 managers and senior staff of selected tertiary institutions in Nigeria out of which a cluster sample of 400 was identified for data collection. A Likert's type 4-point rating scale (Tertiary Institutions Internally Generated Revenue Scale TIIGRS) was constructed, validated and administered on the identified sample. Data were analyzed with Chi-Square $\left(\mathrm{x}^{2}\right)$ Test of Independence and Cramer's v-statistic for hypotheses' testing at the significance level of $p=<0.05$ (Table 1 ). 


\begin{tabular}{|c|c|c|c|c|c|c|c|}
\hline \multirow[t]{2}{*}{ Null Hypotheses } & \multirow[t]{2}{*}{ Mean } & \multirow[t]{2}{*}{ Variance } & \multirow[t]{2}{*}{ S.D. } & \multicolumn{2}{|c|}{ Chi-Sq. ( $\left.x^{2}\right)$} & \multirow[t]{2}{*}{ V-Stat. } & \multirow[t]{2}{*}{ Decision } \\
\hline & & & & Cal. & Crit. & & \\
\hline $\begin{array}{l}\text { Characteristics of companies that excel } \\
\text { in the United States have no significant } \\
\text { relationship with improving the } \\
\text { internally generated revenue capacity } \\
\text { of tertiary institutions in Nigeria }\end{array}$ & 5.00 & 3.27 & 2.11 & 14.32 & 12.592 & 0.61 & $\mathrm{H}_{0}$ Rejected \\
\hline $\begin{array}{l}\text { Characteristics of companies that excel } \\
\text { in the US cannot significantly be } \\
\text { adopted to improve the internally } \\
\text { generated revenue of Nigerian tertiary } \\
\text { institutions. }\end{array}$ & 5.08 & 2.87 & 2.70 & 14.01 & " & 0.58 & $\mathrm{H}_{0}$ Rejected \\
\hline $\begin{array}{l}\text { Nigerian tertiary institutions cannot } \\
\text { significantly go into profitable business } \\
\text { partnerships with private-sector } \\
\text { establishments. }\end{array}$ & 5.08 & 3.20 & 2.79 & 15.37 & " & 0.60 & $\mathrm{H}_{0}$ Rejected \\
\hline $\begin{array}{l}\text { Characteristics of companies that excel } \\
\text { in the US cannot significantly improve } \\
\text { the internally generated revenue of } \\
\text { tertiary institutions in Nigeria. }\end{array}$ & 4.92 & 3.64 & 2.28 & 16.58 & " & 0.62 & $\mathrm{H}_{0}$ Rejected \\
\hline
\end{tabular}

Table 1: Results of Hypotheses Testing

Source: Researchers' Field Work

\section{Results and Discussion}

Null hypothesis I showed Cal. $\mathrm{x}^{2}$ of 14.32 was $\geq$ Crit. $\mathrm{x}^{2}$ of 12.592. Consequently, this hypothesis was rejected. The vstatistic of 0.61 indicated that the characteristics of companies that excel in the United States had significant relationship with improving the internally generated revenue of tertiary institutions in Nigeria.

This association of the variables further confirmed their dependence on each other. This result indicated that the characteristics of companies that excel in the United States of America had a significant relationship with improving the internally generated revenue of tertiary institutions in Nigeria.

Null hypothesis II had Cal. $\mathrm{x}^{2}$ of $14.01 \geq$ Crit. $\mathrm{x}^{2}$ of 12.592. This hypothesis, too, was rejected. The v-statistic value of 0.58 indicated that the characteristics of companies that excel in the US can significantly be adopted to improve the internally generated revenue of tertiary institutions in Nigeria. The v-statistic values of 0.58 between the variables further confirmed their dependence on each other.

Null hypothesis III which stated that Nigerian tertiary institutions cannot successfully go into significant profitable business partnerships with private-sector establishments had Cal. $\mathrm{x}^{2}$ of 15.37 which was $\geq$ Crit. $\mathrm{x}^{2}$ of 12.592 and, consequently, rejected. The v-statistic of 0.60 indicated an association between the variables. This finding also indicated that Nigerian tertiary institutions can successfully go into profitable business partnerships with private-sector establishments. This finding agrees with the arguments of Obasi (2004),Ngwenya (2015) and editorial@universitybusiness.com that tertiary institutions can go into business partnerships, commercialize and take their products to the market.

Null hypothesis IV had Cal. $\mathrm{x}^{2}$ of 16.58 which was $\geq$ Crit. $\mathrm{x}^{2}$ of 12.592 . This hypothesis stated that there were no significant ways which characteristics of companies that excel in the United States of America could improve the internally generated revenue of tertiary institutions in Nigeria. There was a v-statistic of 0.62 which indicated an association between the two variables especially on issues such as joint ventures in research and development, consultancy and other revenue generating ventures (Well, 2009 and Okunamiri, 2015). This result also indicated that there were significant ways which tertiary institutions in Nigeria could improve the internally generated revenue by going into business partnerships with private sector organizations. These findings apply to tertiary institutions in Nigeria but could also apply to tertiary institutions other parts of Africa or elsewhere with the same characteristics as those that obtained in tertiary institutions in Nigeria.

\section{Conclusion}

The researchers concluded that in order for tertiary institutions in Nigeria to improve their internally generated revenue, stabilize their funding, adequately motivate staff and perform optimally, there is need for conscious establishment and sustenance of business partnerships between them and private business organizations within and outside the country. This is what will restore the glory and tertiary institutions and make them more relevant to the economic and industrial development of the country. 


\section{Recommendations}

This paper makes the following recommendations: tertiary institutions should explore available opportunities for establishing joint business ventures with private sector establishments by identifying and creating viable business ventures (Bawakyilenuo, 2013), adopt characteristics of companies that excel in the United States of America to manage their affairs for optimal performance (Collins and Porras, 2002), profitability and sustainable development, explore PPP (Private Public Partnerships) opportunities as well as BOT (BuildOperate and Transfer) arrangements between them and private sector establishments, source funds for capital build up (Ngwenya, 2014) invest and expand of their services and production of goods for sale through partnerships with private business establishments, re-cycleincome generated to beef up their liquidity or cash-flow profiles (Capson, 2008), provide qualitative services or products from research on commercial basis (Awe, 2008); thusgeneratingincome for sustainability and growth and optimal performance and treat employees as co-owners of the institutions by devising reward programmes that motivate them for efficiency, productivity and loyalty to the ideals of tertiary institutions (Byars and Rue, 1997).

\section{References}

i. $\quad$ Awe, A. B. Quality management of universities in Nigeria. In Babalola, J. B. and Ayeni, A. O. (2008). Educational management: theories and tasks; Ibadan: Macmillan Nigeria Publishers Limited.

ii. Bawakyilenuo, S. (2013). Working paper on tertiary education and industrialdevelopment in Ghana, Legon: Institute of Statistical, Social and Economic Research (ISSER). University of Ghana.

iii. Bateman, T.S. and Zeithaml. C.P. (1993). Management: function and strategy; Burr Ridge: Richard D. Irwin, Inc.

iv. $\quad$ Byars, L.L. and Rue, L.W. (1997). Human resources management: New York: McGraw Hill.

v. Capson, C. (2008). Understanding strategic management;England: Pearson Educational Limited.

vi. Cole, G. A. (2005). Personnel and human resources management; London: Thompson Learning.

vii. Collins, J. (2001). Good to great: whysome companies make the leap...and othersdon't; New York: HarperCollins Publishers, Inc.

viii. Collins and Porras (2002). Built to last; New York: McGraw Hill Book Company.

ix. Editorial@Universitybusiness.Com. “30 smart business ideas" (Retrieved: 28/ 7/ 16).

x. Francis, A. (2008). Business mathematics and statistics; Hampshire: Cengage Learning EMEA.

xi. $\quad$ Guest, R. (2004). The shackled continent; London: Pan Books.

xii. Hindle, T. (2008). The economist guide to management ideas and gurus; London: Profile Books Ltd.

xiii. Igwe, S.O. (1990). Professional handbook for teachers; Owerri: New AfricaPublishingCompany Ltd.

xiv. $\quad$ Madumere, S.C. (1989). Statisticaltools for educational management in developing countries; Lagos: JojaPress Ltd.

xv. McClelland, D. C. (1993). The achievement motive in economic growth. In Seligson, M. A. and Passe Smith, J. T. (1993). Development-under-development: the politicaleconomy of inequality; Colorado: Lyme Reinner Publishers, Inc.

xvi. $\quad$ McCormick, E. J. and Tiffin, J. (1974). Industrialpsychology; London: George Allen \&Unwin.

xvii. Ngwenya, B. (2014). Universities, tertiary institutions and their role in ppp initiatives; Bulawayo: Sunday News Online.

xviii. Obasi, E. (2000). The economics of education in Nigeria; NkwogwuMbaise: New Vision Publishers.

xix. Obi, E. C. (2012). Business education and the entrepreneurship educationsynergy for unemploymentreduction in Nigeria, Mediterranean journal of social sciences vol. 3, No. 15; Piazzale Aldo Moro: CEMAS - SapienzaUniversity.

xx. Oku, O. O. (2008,). The concept of human resources management (HRM) in education. In Babalola, J. B. \&Ayeni, A. O (Eds).; Educational management: theories and tasks; Lagos: Macmillan Nigeria Publishers Limited.

xxi. Okunamiri, P. O. (2015). Economics of education: the Nigerian situation; Owerri: Versatile Publishers.

xxii. Osakpa, D. U., Lebo, M. P. and Okonkwo, Dyke A. R. (2016). Managing Nigerian universities for optimal performance: adoption of strategies of companies that excel in the United States of America as analyzed in built to last; Abuja international journal of education and management sciences, vol. 4 no. 1.

xxiii. Udu, A. (2014). Handling entrepreneurship in tertiary institutions in Nigeria; Journal of management sustainability, 4(1), http:/ dx.doi.org/ 10.5539/ ims.y4n1p189.

xxiv. Useem, A. (2015). 5 effective ways of partnership, (Retrieved: 28/7/ 16).

xxv. Zander, A.(1990). Effective social action by community groups; San Francisco: Jossey-Bass Publishers. 